\title{
Epidemiological study on tobacco smoking among university students in Damascus, Syrian Arab Republic
}

\author{
W. Al-Kubaisy, ${ }^{7}$ N.N. Abdullah, ${ }^{7}$ H. Al-Nuaimy, ${ }^{2}$ G. Halawany ${ }^{3}$ and S. Kurdy ${ }^{3}$
}

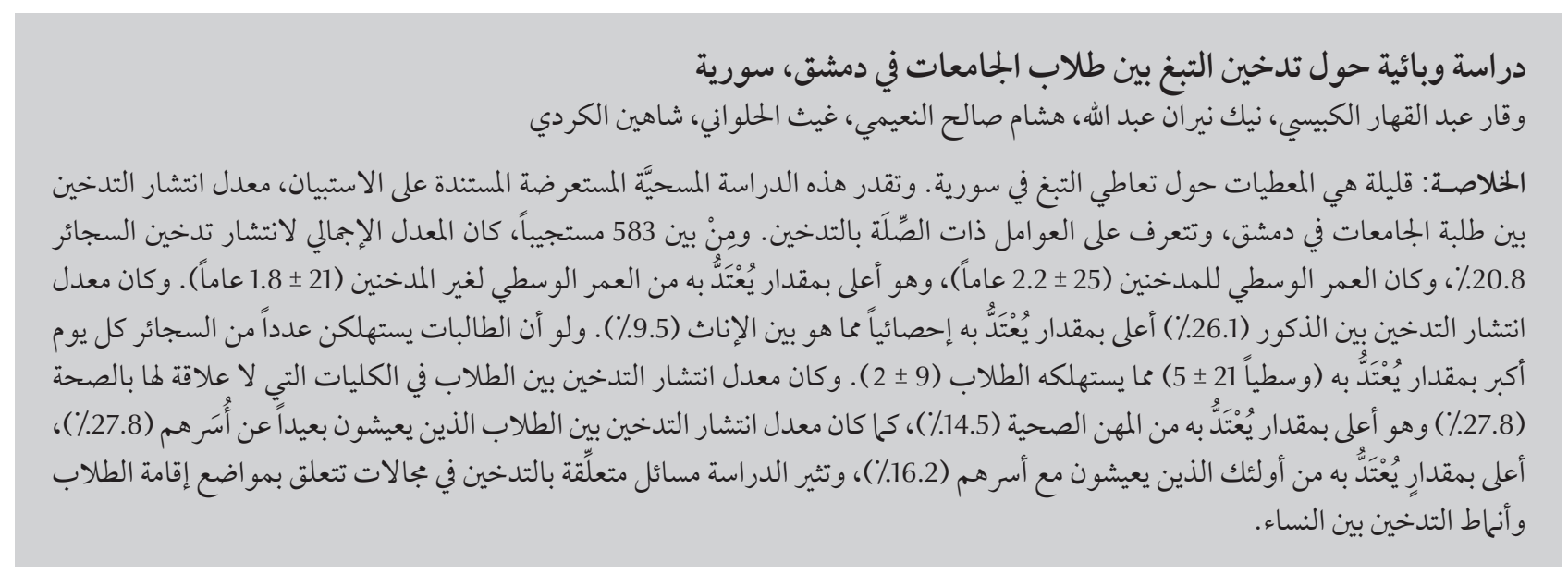

ABSTRACT There is a lack of data on tobacco use in the Syrian Arab Republic. This cross-sectional questionnaire survey estimated the prevalence of smoking among university students in Damascus and identified factors related to smoking. Among the 583 respondents, the overall prevalence of cigarette smoking was $20.8 \%$. The mean age of smokers [25 (SD 2.2) years] was significantly higher than non-smokers [21 (SD 1.8) years]. Smoking prevalence among males (26.1\%) was significantly higher than among females (9.5\%). However, female students consumed a significantly higher number of cigarettes per day than did males [mean 21 (SD 5) versus 9 (SD 2)]. The smoking prevalence among students in non-health faculties (27.8\%) was significantly higher than that of health professional students (14.5\%) and was higher among students living away from their families (27.8\%) than those living with their families (16.2\%). The study raised concerns about smoking in student residences and women's smoking patterns.

\section{Étude épidémiologique sur la consommation de tabac chez les étudiants à Damas (République arabe syrienne)}

RÉSUMÉ Les données sur la consommation de tabac sont rares en République arabe syrienne. La présente enquête transversale par questionnaire a estimé la prévalence du tabagisme chez les étudiants en université dans la ville de Damas et a identifié les facteurs qui y sont liés. Sur un total de 583 répondants, la prévalence globale du tabagisme était de 20,8 \%. L'âge moyen des fumeurs [25 ans (E.T. 2,2)] était significativement plus élevé que l'âge des nonfumeurs [21 ans (E.T. 1,8)]. La prévalence du tabagisme chez les étudiants de sexe masculin (26,1 \%) était nettement plus forte que celle des étudiantes (9,5\%). Toutefois, les étudiantes consommaient un nombre bien plus important de cigarettes par jour que les étudiants [moyenne 21 (E.T. 5) contre 9 (E.T. 2)]. La prévalence du tabagisme chez les étudiants inscrits dans des facultés non spécialisées en sciences de la santé (27,8\%) était bien supérieure à celle des étudiants en santé (14,5\%) et supérieure chez les étudiants vivant loin de leur famille (27,8 \%) par rapport aux étudiants vivant en milieu familial (16,2 \%). L'étude a soulevé des inquiétudes concernant le tabagisme dans les résidences universitaires et les modes de consommation du tabac par les étudiantes.

${ }^{7}$ Department of Population and Preventive Medicine; ${ }^{2}$ Department of Physiology, Faculty of Medicine, Universiti Teknologi MARA, Malaysia (Correspondence to W. Al-Kubaisy: waqarabd@yahoo.co.uk).

${ }^{3}$ Department of Community Medicine, Syrian International University for Sciences and Technology, Damascus, Syrian Arab Republic.

Received: 28/07/10; accepted: 06/03/11 


\section{Introduction}

Despite the well-known health risks of tobacco smoking [1-3] there are increasing numbers of youths starting to smoke at an earlier age $[4,5]$. Several studies have shown that smoking initiation during adolescence increases the likelihood of continued smoking during young adulthood and also decreases the chance of quitting [5-8]. Moreover, the prevalence of smoking among females is increasing worldwide, especially in developing countries.

Theories suggest that young people begin smoking to express their transition into adulthood. Some may smoke to adhere to their social group in the process of developing their own social network [7]. Other reasons are feelings of insecurity and to resolve mental stress and other emotional problems [6-8]. Women are also more likely to believe that smoking can control their weight $[2,9]$. The Theory of Triadic Influence stipulates that factors from 3 different levels of contacts can influence smoking onset among youth: individual characteristics (e.g. age and sex), characteristics of the immediate social environment (e.g. friends and family members) and characteristics of the broader social environment (e.g. school community) [4]. Therefore, identifying subgroups of youth who may be at greater risk than others to develop a nicotine habit is an important step forward in preventing smoking initiation, and controlling tobacco use [9].

Recent large-scale public health interventions in industrialized countries have contributed to a substantial decline in cigarette smoking among adults and adolescents [10]. This has not been the case in developing countries, including countries in the Middle East, where the prevalence of smoking continues to increase [11].There is a lack of population-based data on tobacco use in Syrian Arab Republic. The aims of this study were to estimate the prevalence of smoking among students of the Syrian
International University for Science and Technology and to identify factors that may be related to smoking behaviour.

\section{Methods}

\section{Setting and sample}

A cross-sectional study was conducted from 1-30 October 2007. The study population was students of the Syrian International University for Sciences and Technology located in the Sahnayah district of Damascus $(n=1200)$. This private university was newly established and consisted of 6 faculties: medicine, dentistry, pharmacy, petroleum engineering, business administration and computer engineering and informatics. A stratified cluster sampling of 3 stages was implemented for the sample collection. In the first stage, students from each faculty were stratified according to their level of study (first, second or third year). Individuals were selected proportional to the number of students in each level. In the second stage the individuals were stratified again and selected proportionally according to sex. In the final stage, the chosen students from all faculties were grouped into clusters of manageable size. A simple random sample of 774 was collected.

\section{Data collection}

The selected individuals were informed about the purpose of the study and assured about the anonymity of the questionnaire and that the information would be used only for research purposes. A pre-tested questionnaire was designed based on those used in similar surveys $[9,12]$ and distributed to all selected participants. The questionnaire included information about cigarette smoking status (current and past), the average number of cigarettes smoked daily and sociodemographic characteristics (age, sex, living away from family).

A current smoker was defined as a person who had smoked at least 100 cigarettes during his/her lifetime and was currently smoking. A former smoker was a person who had smoked at least 100 cigarettes during his/her lifetime but reported to have quit smoking. Individuals reporting either smoking < 100 cigarettes during their lifetime or never having smoked were categorized as non-smokers [13].

In order to maximize the response rate, the questionnaire returns were checked daily by trained researchers and if data were missing the questionnaire was immediately returned to the respondent for completion.

\section{Statistical analysis}

The data were analysed using SPSS, version 16.0. Data were presented in simple measures of frequencies, the significance of difference between proportions and means was tested using chi-squared test and $t$-test respectively, with $P$-value $<0.05$ as the level of significance.

\section{Results}

Of the 745 students selected to participate in the study, 162 students (131 males and 31 females) did not return the questionnaire, refused to participate or could not be located during the data collection period. The analysis was therefore based on 583 students (394 males and 189 females) (response rate $75.3 \%$ ). The mean age of the participants was 21 [standard deviation (SD) $1.2]$ years (range 17-28 years).

A total of 121 students (20.8\%) reported being current smokers ( $\mathrm{Ta}-$ ble 1). The mean age of non-smokers [21 (SD 1.8 years] was significantly lower than that of smokers [25 (SD 2.2) years $](t=2.1, P<0.025)$.

The smoking prevalence among male students (26.1\%) was significantly higher than that among females (9.5\%) $\left(\chi^{2}=20.4, P<0.001\right)($ Table 1$)$. Thus, a male student was at 3 times higher risk of becoming a smoker $(\mathrm{OR}=3.36,95 \%$ CI: $1.96-5.73, P<0.001)$. Two males 


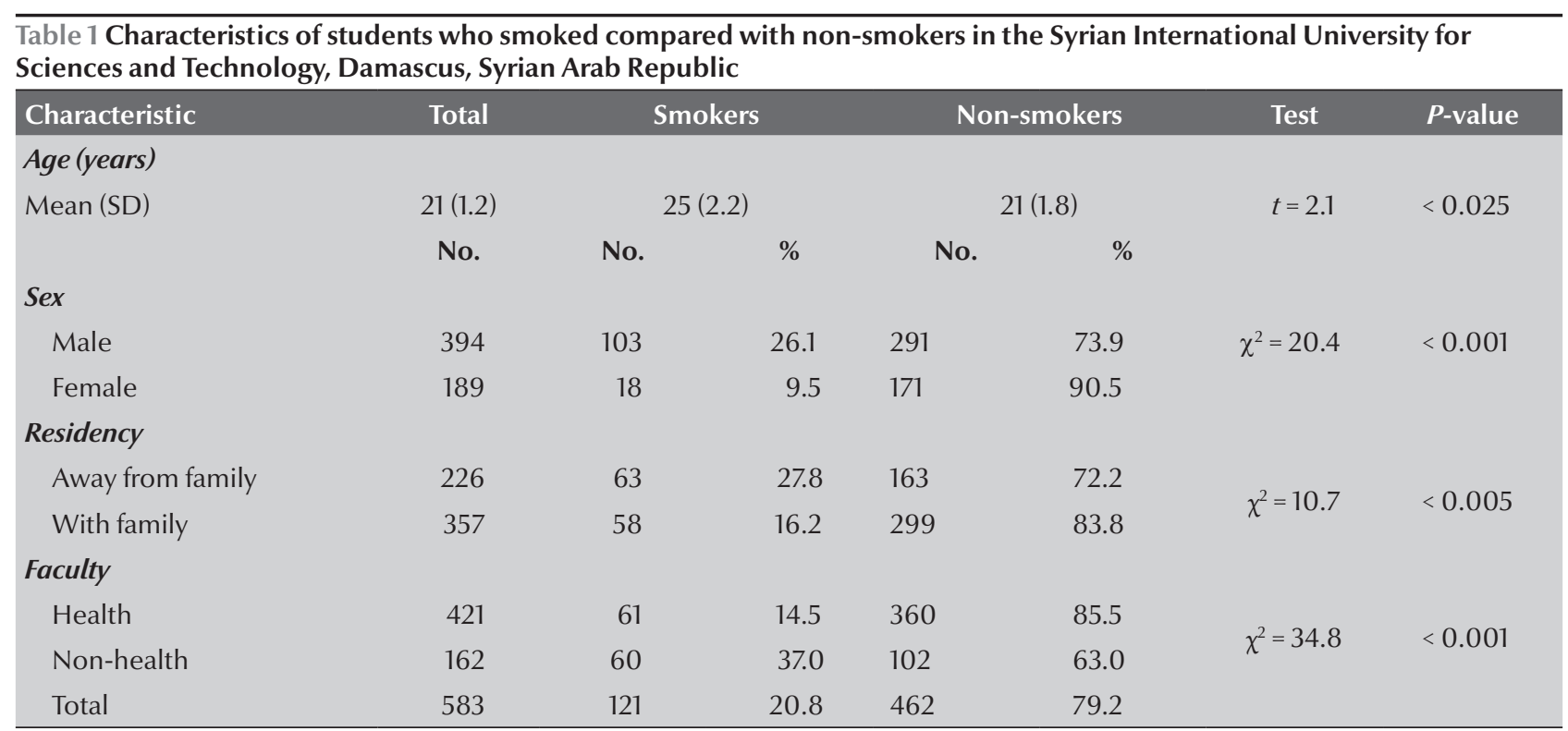

$S D=$ standard deviation .

and none of the female students were ex-smokers. The age range of female smokers (17-23 years) was smaller than that of male smokers $(17-28$ years), while non-smokers of both sexes were in the same age range (17-20 years). In respect to the quantity of tobacco consumed, female students consumed a significantly higher mean number of cigarettes per day than did male students [21 (SD 5) versus 9 (SD 2)] $(t=17.7, P<0.005)$.

Students studying in non-health faculties (computer engineering, administrative, petroleum engineering) had a significantly higher rate of smoking $(37.0 \%)$ than students in health faculties (medicine, dentistry and pharmacy) $(14.5 \%)\left(\chi^{2}=34.8, P<0.001\right)$ (Table 1). The prevalence of smoking was significantly higher among students living in private apartments away from their families (27.8\%) than those who were living with their families (16.2\%) $(\mathrm{OR}=1.99,95 \%$ CI: 1.32-2.98) (Table 1).

\section{Discussion}

Cigarette smoking and other forms of tobacco use among children and adolescents is a significant public health concern. The prevalence of smoking at this university (20.8\%) was higher than that reported among Syrian students in 2008 (10.9\%) [14]. A similar trend of relatively high and rising smoking prevalence has been observed among young people in ASEAN countries [9]. The prevalence of smoking in our study, however, was much lower than that in Kuwait among individuals aged 20 and 30 years ( $37.1 \%$ and $50 \%$ respectively) [15].

The mean age of smokers in our study (25 years) was significantly higher than non-smokers (21 years). We had no data on the age of initiation of smoking but current smokers in this study may have started smoking before entry to the university. It could also be attributed to the higher smoking prevalence among non-health professional students who were older than health professional students [personal observation]. However, the mean age of smokers in our study was higher than that reported for students in Malaysia $(18.6$ years) and Kuwait (18 years) $[15,16]$.

Cigarette smoking prevalence among males was about 3 times higher than among females $(26.1 \%$ versus 9.5\%). In Saudi Arabia the prevalence of smoking was more than 20 times that of females (21.2\% versus $0.9 \%$ ) [17]. The prevalence of cigarette smoking among females in our study (9.5\%), however, was lower than that reported among female university students in Saudi Arabia (11\%) and the United States (12\%) $[18,19]$. On the other hand, the prevalence of cigarette smoking among females in this study was higher than that reported among women in a previous Syrian study during 2004 (7.4\%) [14]. There is other evidence from Arab countries of significantly higher rates of cigarette smoking among males than females, which as been attributed to the social stigma attached to cigarette smoking in women [17]. However, several factors seem to be driving an increase in female smoking, especially in developing countries. The most important factor may be the rise in spending power among girls and women, which is making cigarettes more affordable. Social and cultural norms that have traditionally prevented women in many countries from smoking are also weakening, rendering smoking among women more socially acceptable. Greater female autonomy and changes in women's roles have been associated with smoking uptake in countries such 
as the United States, prompting predictions of a similar pattern in developing countries [2].

Interestingly, females in our study smoked a significantly higher mean number of cigarettes per day compared with male smokers ( 21 versus 9 per day). This rate was higher than reported in United States among university female students and was also higher than in a study among girls and women in South-East Asia [9]. Reasons for the higher cigarette use among women might be related to their body perceptions. Increased concerns about body weight and dieting have been associated with both depression and smoking among adolescents, particularly girls [20]. Women are more likely than men to believe that smoking helps to control their weight, and this may be more pronounced in those with eating disorders [21]. In addition, uptake of smoking may be influenced by media messages that promote smoking with images of freedom, emancipation, slimness and glamour [9].

The students' residential status was another indicator of smoking in our study. Significantly more smokers (31.6\%) than non-smokers (16.2\%) were living away from their parents. This supports the theory that the social environment surrounding youth plays a major role in smoking behaviour. Both parental and peer smoking have been shown to be important predictors of smoking [19,22]. Students living away from their parents may be subject to a higher degree of peer influence compared with those living with their parents. Peers' smoking was associated with current smoking among university students in Syrian Arab Republic [12]. In the study, people who lived away from their families were about twice as likely to be smokers as people residing within their families, which agrees with the findings of a Kuwait study [15]. A smoke-free environment is likely to deter students from smoking and can also protect students from second-hand smoke; exposure to smoke in public areas was reported to be the main form of environmental tobacco exposure among adolescents in Cambodia [23].

Because the study was conducted in only one locality, the findings could not be extrapolated to the general student population of Syrian Arab Republic. There may have been underreporting of smoking among students particularly female students, due to the stigma of women smoking in Arab culture.

In conclusion, smokers in our study were older than non-smokers suggesting that it is important to provide smoking control interventions and health education for youths at an earlier age before they begin smoking. As students living at home were more likely to be smokers than those living in university residences, academic institutions should be encouraged to provide smoke-free college residences. Finally, although this cross-sectional study did not provide evidence of rising rates of women smoking over time, the finding that those women students who smoked were smoking more heavily than men is a concern. Developing countries have reported increasing rates of smoking among women and the government needs to treat tobacco use among women as a priority health issue.

\section{References}

1. Doll $\mathrm{R}$ et al. Mortality in relation to smoking: 40 years' observations on male British doctors. British Medical Journal, 1994, 309:901-911.

2. The health consequences of smoking. A report of the Surgeon General. Atlanta, Georgia, Centers for Disease Control and Prevention, 2004.

3. Reducing the health consequences of smoking: 25 years of progress. A report of the Surgeon General. Washington DC, United States Department of Health and Human Services, 1989.

4. Koushki PA, Bustan M. Smoking, belt use, and road accidents of youth in Kuwait. Safety Science, 2006, 44:733-746.

5. Chassin $\mathrm{L}$ et al. The natural history of cigarette smoking: predicting young-adult smoking outcomes from adolescent smoking patterns. Health Psychology, 1990, 9:701-716.

6. Ershler $\mathrm{J}$ et al. The quitting experience for smokers in sixth through twelfth grades. Addictive Behaviors, 1989, 14:365378.

7. Escobedo LG et al. Sports participation, age at smoking initiation, and the risk of smoking among US high school students. Journal of the American Medical Association, 1993, 269:13911395.

8. Pierce JP et al. Smoking initiation in the United States: a role for worksite and college smoking bans. Journal of the National Cancer Institute, 1991, 83:1009-1013.
9. Kin F. Smoking among girls and young women in ASEAN countries: a regional summary. Bangkok, Southeast Asia Tobacco Control Alliance, 2009.

10. Brownson RC et al. Demographic and socioeconomic differences in beliefs about the health effects of smoking. American Journal of Public Health, 1992, 82:99-103.

11. Moody PM, Al Bustan MA, Manav V. Smoking or health? International trends and marketing of tobacco and possible interventions. International Quarterly of Community Health Education, 1993, 14:299-314.

12. Almerie $M Q$ et al. Cigarettes and waterpipe smoking among medical students in Syria: a cross-sectional study. International Journal of Tuberculosis and Lung Disease, 2008, 12:1085-1091.

13. Cigarette smoking among adults-United States 1992, and changes in definition of smoking. Journal of the American Medical Association, 1994, 272:14-16.

14. Maziak W et al. Characteristics of cigarette smoking and quitting among university students in Syria. Preventive Medicine, 2004, 39:330-336.

15. Moody PM et al. Factors associated with the initiation of smoking by Kuwaiti males. Journal of Substance Abuse, 1998, 10:375-384.

16. Third National Health and Morbidity Survey (NHMS III) 2006. Executive summary. Putrajaya, Ministry of Health Malaysia, 2008. 
17. Jarallah JS et al. Prevalence and determinants of smoking in three regions of Saudi Arabia. Tobacco Control, 1999, 8:53-56.

18. Garcia M et al. Global cancer facts and figures 2007. Atlanta, Georgia, American Cancer Society, 2007.

19. Merdad LA, Al-Zahrani MS, Farsi JMA. Smoking habits among Saudi female university students: prevalence, influencing factors and risk awareness. Annals of Saudi Medicine, 2007, 27:366-369.

20. Larsen JK, Otten R, Engels RC. Adolescent depressive symptoms and smoking behavior: the gender-specific role of weight concern and dieting. Journal of Psychosomatic Research, 2009, 66:305-308.
21. McKee SA et al. Smoking for weight control: effect of priming for body image in female restrained eaters. Addictive Behaviors, 2006, 31:2319-2323.

22. Weitzman M, Gortmaker ST, Sobol A. Maternal smoking and behavior problems of children. Pediatrics, 1992, 90:342-349.

23. Rudatsikira E, Siziya S, Muula AS. Prevalance and predictors of environmental tobacco smoke exposure among adolescents in Cambodia. Indian Journal of Community Medicine, 2010, 35:100-104.

\section{Exposure to second-hand smoke in the Eastern Mediterranean Region}

WHO released a report entitled Exposure to second-hand smoke in selected public places in the WHO Eastern Mediterranean Region during the 15th World Conference on Tobacco or Health, held in Singapore, from 20 to 24 March 2012. The report contains the results of a pilot study conducted in 11 countries of the Region that documented second-hand smoke levels in enclosed public places to assess compliance with smoke-free policies and legislation. Based on the findings from the participating countries, the report suggests steps that can help improve enforcement of $100 \%$ smokefree policies.

This document is available at: http://applications.emro.who.int/dsaf/emropub_2012_1357.pdf 